\title{
European Regions and Entrepreneurial Ecosystems in the Context of the New Sustainable Development Goals
}

\author{
Roxana Voicu-Dorobanțu \\ Bucharest University of Economic Studies, Bucharest, Romania
}

Correspondence should be addressed to: Roxana Voicu-Dorobanțu; Rovodo@Gmail.Com

Received date: 3 April 2015; Accepted date: 17 September 2015; Published date: 7 September 2016

Academic Editor: Adela Coman

Copyright (C) 2016. Roxana Voicu-Dorobanțu . Distributed under Creative Commons CC-BY 4.0

\begin{abstract}
Starting from the basic concept of entrepreneurial ecosystem, corroborated with the new Sustainable Development Goals to be decided upon in September 2015, this paper describes the situation of the regions of the European Union, in particular Romania, and their clustering based on development indicators. The purpose is to underline possible policies, based on two relevant pillars: territorial capital, defined as all economic, cultural, environmental and social assets that ensure the potential development of the characterized area, i.e. the region, and the subjective opinion regarding current policies for the regions.
\end{abstract}

Keywords: innovative entrepreneurial ecosystem, public policy, territorial capital, European Union

\section{Introduction}

In September 2015, at the Summit of the United Nations are proposed toward adoption and desired to be met by 2030 a total of 17 sustainable development goals (SDGs), successors to the Millennium Goals, reflecting the desire of global assurance of an optimal existence in the future. Of these, five are closely related to global competitiveness, and may be measured directly through the pillars of the Global Competitiveness Index from the World Economic Forum. Cost is a major issue for the accomplishment of these tasks, as it is estimated at about 2,500 billion (UNCTAD, 2014) annually. Such an approach is necessary conjugate that synergy, creativity and funding to fulfill their roles globally optimal. In this context, the need for accurate targeting exists so as not to waste time and money resources

Industrial policies for growth and / or development alongside the economic theories on which they are based have been created mostly post-World War II and have

Cite this Article as: Roxana Voicu-Dorobanțu (2016)," European Regions and Entrepreneurial Ecosystems in the Context of the New Sustainable Development Goals", Journal of Eastern Europe Research in Business and Economics, Vol. 2016 (2016), Article ID 145844, DOI: 10.5171/2016.145844 
been ever since at the center of the economic and political debate. In this context, after the collapse of the communist economic system in 1989-1990, Stiglitz and Greenwald (2014) evaluate and provide a critical overview of the Washington Consensus policies, focused on "static efficiency without considering the consequences of innovation and learning". It is thus considered that technological progress and regional development were often determined by external factors, without being affected by the economic policies explicitly targeted. It is a positive sign that, for a better understanding of the growth, development and linked policies, the importance of active factors is highlighted, such is the case for "technological progress" (Solow 1956), "learning by doing" (Arrow 1962), "human capital" (Becker 1964), "information asymmetry" (Akerlof 1970), "innovation "(Drucker 1985)," creative class "(Florida 2002), and" knowledge "and" entrepreneurship ", etc.

But for a better understanding of the complex phenomena that contribute directly or indirectly to economic growth and development, regardless of scale (local, regional, national, European or global), there is the need to look beyond the classic reductionists factors of production "land, labor, capital" and to start from a minimal taxonomy of factors subsumed to the concepts of "territorial capital" and regional entrepreneurial ecosystem. Special attention should be given to the concept of "entrepreneurial learning" - as a special type of learning, training and self-training, for 'innovative entrepreneurship'.

\section{Literature Review}

\section{Innovative entrepreneurial ecosystems - efficient structures for regional development policies}

Rooted in constant research trend seeking similarities between entities and systems to enable in-depth understanding of the completely unknown, and based on Moore's
1993 work "Predators and Prey: a New ecology of competition", nowadays may be observed a strong orientation to compare business systems with biological systems, the so-called "logic living systems" (Dinga, 2007). The scientifically defined as a collection of agents acting selfish or selfless, bringing added value and synergy learn from others, a "business ecosystem" became recently a buzz word in most academic and institutional mediums.

Anggraeni, Hartigh and Zegveld (2007) argue that the conceptual boundaries that clarify the definition of these logical systems are superficial; however, research on business ecosystems, business ecosystems, or regional innovation is in its first stages. A defining element, however, is that synergistic movement towards creating value, harnessing the creative potential, reducing existing externalities and efficiently using capital: human, economic and environmental (territorial capital) (Andriani, 2013; Battistella, Colucci and Nonino, 2012).

The components of a business or entrepreneurial ecosystem are actors, flows (such as financial and knowledge flows) and the dynamic of the two (Iansiti \& Levien, Iansiti \& Richards, 2002, 2004, 2006). The knowledge flow is also used in explaining the diffusion of innovation and academic research (universities and research centers are crucial actors in the ecosystem) (Pamfilie, Giusca, Cotton, 2014).

Isenberg (2010) proposes a number of new measures that governments should take (in the form of policies, but not only) to develop entrepreneurial ecosystems in their regions or states, i.e. not emulate Silicon Valley (one case specific, unrepeatable), to adapt to local conditions, involving all components of the ecosystem stakeholders from an early stage to encourage potential players to focus on successes, working on cultural change, to focus on organic growth ecosystem components do not create clusters artificially 
legislative reform institutional structures and specific public policies.

\section{Territorial capital - a fundamental concept for targeting regional development policy}

Focus, structure and human capital flows, as well as high level of education in a region are indicators of the dynamics of that particular region in its growth. Researchers and specialists are key players for innovation and development requires high rates of this particular element. Concentration of human capital with high level of education generally correlates with the level of development. However, research over the past 20-25 years shows that, particularly research and development efforts (and closely related to these efforts, in education) did not consistently correlate positively with regional growth. Leaning on this, Capello (2011) emphasizes the need to widen the focus of the research towards territorial capital (as defined by OECD in 2001), whose components are grouped by Camagni (2008) in the following nine categories: "Private fixed capital stock; Pecuniary externalities (hard); Toll goods (excludable); Relational private services operating on: external linkages for firms, transfer of R\&D results; University spin-offs; Human capital: entrepreneurship, creativity, private knowhow; Pecuniary externalities (soft) Proprietary networks; Collective goods: landscape, cultural heritage (private „ensembles"); Cooperation networks: strategic alliances in $\mathrm{R} \& \mathrm{D}$ and knowledge; $\mathrm{p} / \mathrm{p}$ partnerships in services and schemes; Governance of land and cultural resources; Relational capital: cooperation capability (trust); collective action capability (participation); collective competencies; Resources: natural cultural (punctual); Social overhead capital: infrastructure; Agencies for R\&D transfer; Receptivity enhancing tools; Connectivity; Agglomeration and district economies; Collective action: conventions; behavioral codes; representations; values". The same authors observed that a major cause of this discrepancy is mismanagement of knowledge, insufficiently coordinated with other elements of territorial capital.

The more refined investigated the regional structure of human capital and its development as part of the territorial capital, the best the glimpse into the current status and the real possibilities of development in terms of endogenous growth theory (Lucas 1988, Romer, 1990) and the theory of endogenous development. These related to the regional development policy as a response of local actors to the challenges of globalization, emphasizing the decisive role of culture and local institutions on seeing investment in human capital oriented towards key activities to strengthen local economic actions and attract extra-regional economic activities (Capello, 2007).

One aspect insufficiently or only marginally treated in these recent approaches based on the concept of territorial capital is that the generation and acquisition of knowledge cannot reach its full economic potential and thus benefit growth in the absence of entrepreneurs able to transform innovations into new products or significantly improved compared to the standards of a market increasingly competitive.

\section{Research Methodology}

The literature review outlines the conceptual framework and the context in which this research was conducted on the role of entrepreneurship driven by policy mechanisms for the growth of less developed regions. The first part of this paper stresses the crucial role for the production process and knowledge transfer of the territorial capital that entrepreneurship plays in a region and that it is essential to synchronize all four subcomponents of human capital: creation (research -designing), application (embedded expertise / specialization, professionalization) pecuniary externalities and entrepreneurship. Preliminary research in this direction points out that there is a dysfunction of human capital formation due 
to the weak performance of innovative entrepreneurship. Apparently, a strategy for treating this dysfunction could be the increase in the number of actors with the function and skills to research and design and in the number of innovative entrepreneurs. It is necessary for a like strategy to combine the two growth strategies (endogenous growth and endogenous development) synergistically in a process to involve other components of territorial capital, making it autocatalytic.

The sign of the success of this strategy of autocatalytic re-coupling between the creative and entrepreneurial subcomponents of human capital part of the territorial capital would increase spin-offs and innovative start-ups, both of the purely economic kind (designed exclusively for profit) as well as impact-oriented (targeting social, ecological effects alongside economic viability). This can be achieved but only with entrepreneurs trained to be sufficiently creative and responsive to environmental creativity and creative scientists responsive enough to the demands and opportunities of the business environment. Therefore, it is required to initialize and develop an appropriate formative process.

Based on these considerations, an important component of this research focused on identifying the learning needs of typical actors of the innovation system and potential entrepreneurs, especially in terms of entrepreneurial culture, in order to identify weaknesses that were expected to be present in the Romanian society amid chronic shortage of innovative entrepreneurial performance. Assessment of attitudes towards entrepreneurship is not new, being regularly evaluated from various perspectives, one of the latest being the one proposed by Nistoreanu and George (2014) on the perception of teachers and students on entrepreneurship education in economic and business oriented study programmes. Thus, the following data collection events took place in 2013 and 2014, supported by project IZERZO_142306/1: A) an investigation based on interviews conducted with actors typical to the open innovation system (representatives: authorities, academic and research institutions, businesses, nonprofit organizations, funders, service providers and networking innovation consultancy); B) a questionnaire-based research aimed at a sample of 385 young potential entrepreneurs between 16 and 25 years in three regions (Bucharest-Ilfov, Center, South-East) and a reference sample with the same characteristics in France and Switzerland (67 respondents). The questionnaire was designed to be considered valid in developed countries in terms of entrepreneurial experience, similar to that provided for self-evaluation by the Business Development Bank of Canada. This questionnaire contains 50 questions that required answers based on a Likert scale of 1-4 $(1$ = strongly disagree, $4=$ strongly agree), and allow characterization of the entrepreneurial profile of the population investigated from three main perspectives: 1) motivation, 2) attitudes, and 3) skills. The questionnaire and the subsequent investigation is based on the assumption that an entrepreneurial-oriented education and knowledge transfer system is as effective as the increase in entrepreneurial potential of its "clients"/users, individuals with the intention to start an entrepreneurial endeavor. The components of the questionnaire are highlighted in Figure 1. 


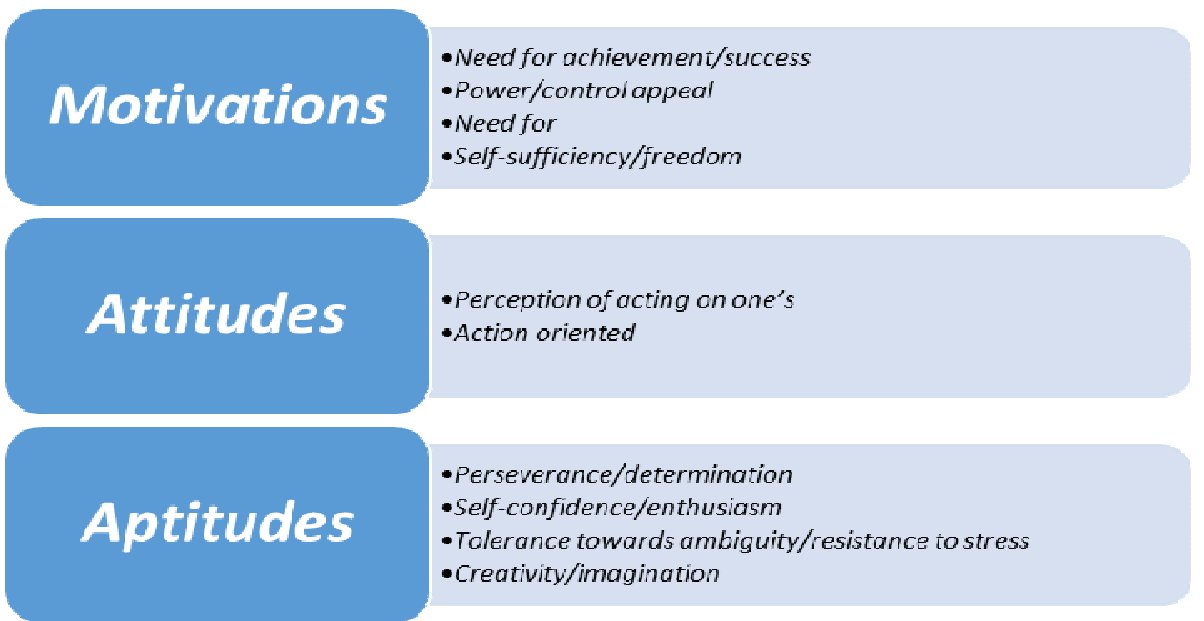

Source: author`s adaptation of the Business Development Bank of Canada questionnaire (2013)

\section{Figure 1: Evaluation perspectives of entrepreneurship}

As a target for the analysis, the elements that reveal the potential for a low profile business performance, according to different groups, are compared. The analysis was made in terms of ranking obtained by applying a score calculated as the average of nonbusiness responses. This was done after normalization to a unit interval, so that the value "1" indicates a pronounced entrepreneurial weakness.

\section{Results and Discussions}

Romania's position from the point of view of human capital as a component of territorial capital

Regions and developed countries have the capacity to generate new business majors, new courses of specialization and new specialists in applied research. By this action, they are perceived as highly innovative regions, interpreted as attractive and therefore recipients of lucrative streams professionals and entrepreneurs from other regions. For example, the UK has attracted over the past decade more than 76,956 professionals and has lost 21,519 and under
Financial Times, about 1 in 7 British companies that were operating in 2013 were founded by immigrants. However, between 2004 and 2012 the number of researchers per hundred thousand people in this country rose to 20.7 (from 381.7 to 402.4). At the opposite end of the spectrum, one may find two categories of countries:

- Countries with a negative balance in human capital flows and an increasing number of researchers. $\rightarrow$ An active effort to generate a significant knowledge flow

- Countries with a negative balance in human capital flows and a decreasing number of researchers $\rightarrow$ countries that are still in a phase of economic dismantling that either need to generate political will for knowledge development, or, if this exists, to propose and implement an effective strategy towards achieving this goal.

In view of the above, it is seen that among European Union countries only Romania suffers from a decline in the number of researchers (see Fig. 2). 
There is a chronic decline, according to the World Bank data (2013), between 1996, when the number of researchers per hundred thousand inhabitants was 133.6 to 2012, which boasted a decade low of 82.8 researchers per hundred thousand inhabitants, which is also the lowest figure in Europe, with the second lowest country, Bulgaria, accounting for nearly double the number of researchers with 155.2 per hundred thousand inhabitants.

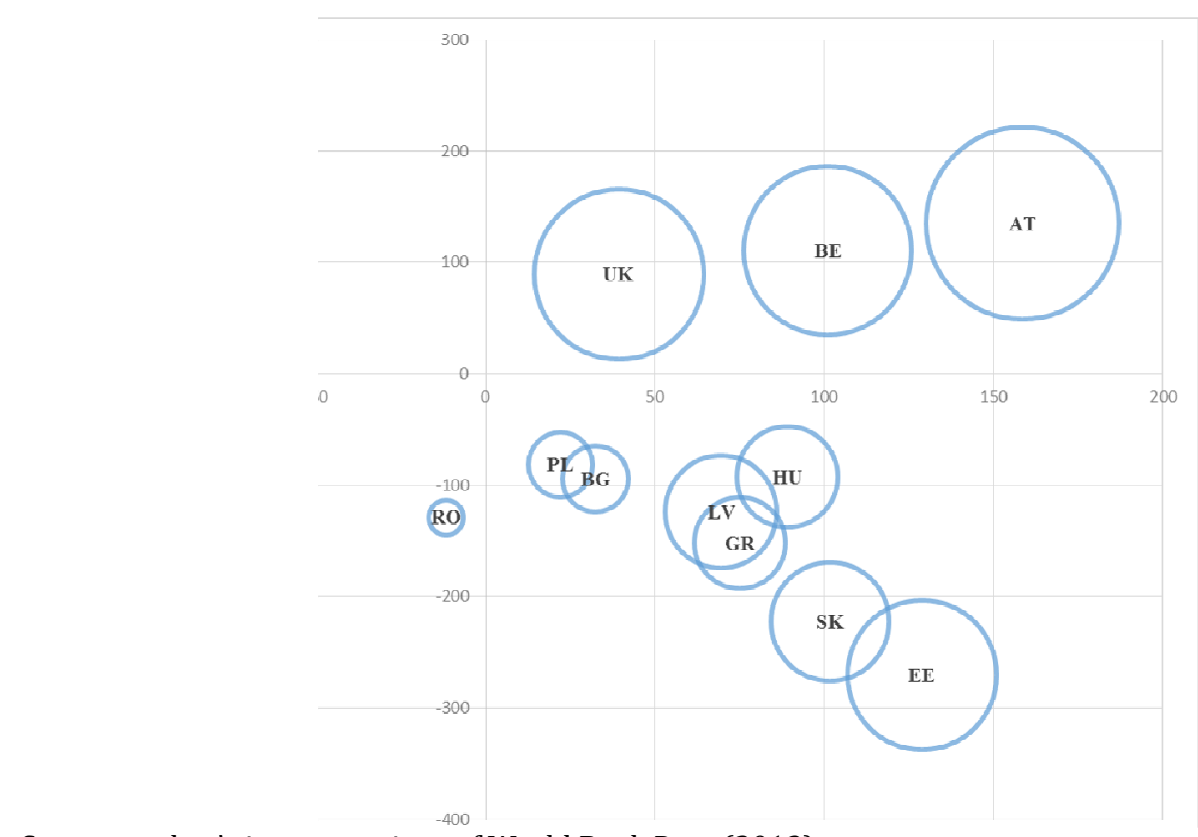

Source: author's interpretations of World Bank Data (2013)

Figure 2: Percentage of researchers and specialist flow balance in $11 \mathrm{EU}$ countries (top 3 performers and top 8 counter performers): Balance of specialist between 2003-2012 (at $100 \mathrm{k}$ inhabitants) versus Increase in number of researchers (at 100k inhabitants) in the same period. The circle represents the number for researchers per $100 \mathrm{k}$ inhabitants in 2012.

This highlights an extremely poor human capital potential generation and valorization of local entrepreneurial projects, evidenced by start-ups with substantial economic impact. This number is also very low compared to the potential of other EU countries, as is illustrated in Fig. 2 and Fig. 3. 


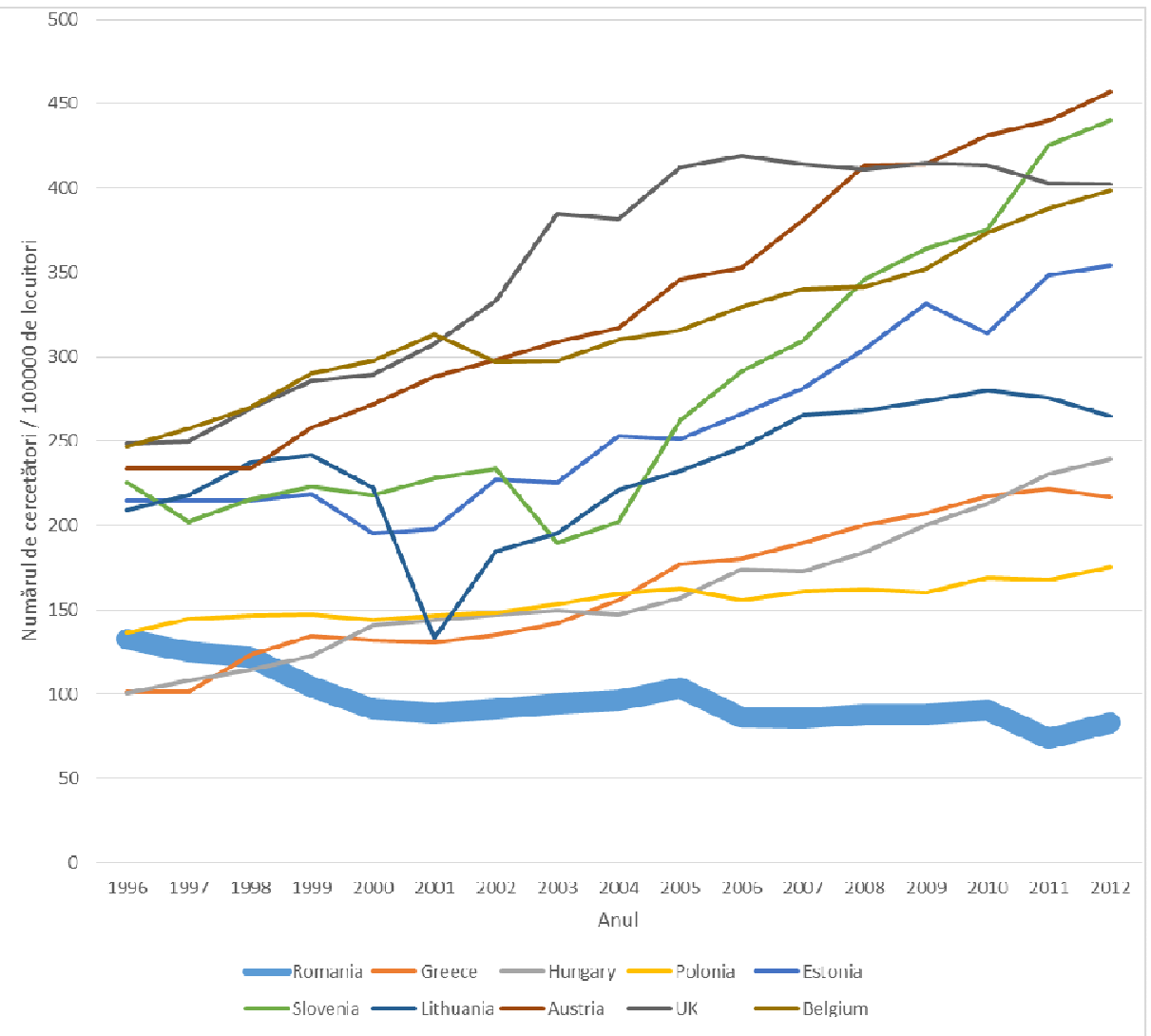

Source: author's interpretations of World Bank Data (2013)

Figure 3: Evolution in the number of researchers in Romania between 1996 and 2012

The opinions and attitudes of potential entrepreneurs - a determining factor in the development of a regional innovative entrepreneurial ecosystem

Initially, the survey was conducted on a number of 385 business undergraduate and graduate students, potential entrepreneurs, in three Romanian regions. The main investigation of these answers to this survey prompted the conclusion that the three regionally differentiated groups are homogeneous. The fundamental shortcomings of the entrepreneurial profile, as noticed in the first phase of exploration, have been demonstrated to be identified with motivation and skills.

The results of the survey with respect to the Romanian sample were interpreted into an analysis, which shows that there is no trust from the potential entrepreneurs' point of view in their own particular capacity to finish tasks and attain objectives. This shows as an absence of motivation joined with an absence of capacity to endure ambiguity and uncertainty, and deal with the anxiety of vulnerability and risk. This is particularly appropriate if the region or nation is immature / undeveloped, and where social and financial environment is insecure, on the 
grounds that the transition to a developed country is still ongoing.

It rose as a valid theory that enhanced access to financing tools for startups and young potential entrepreneurs may lead to a significant increment to the entrepreneurial endeavor and motivation. Accordingly, this could trigger a positive response that could prompt empowering learning entrepreneurial society, and add to the improvement of an entrepreneurial culture all the more successfully.
In order to validate this hypothesis, the same survey has been applied to similar homogenous respondents in developed societies, France and Switzerland. This approach highlights two elements: there is a difference in motivation and a clear distinction in the approach to risky endeavors without a significant amount of seed money. Also, developed countries' respondents have a propensity for leadership as well as a different approach to stress as a driver for creativity.

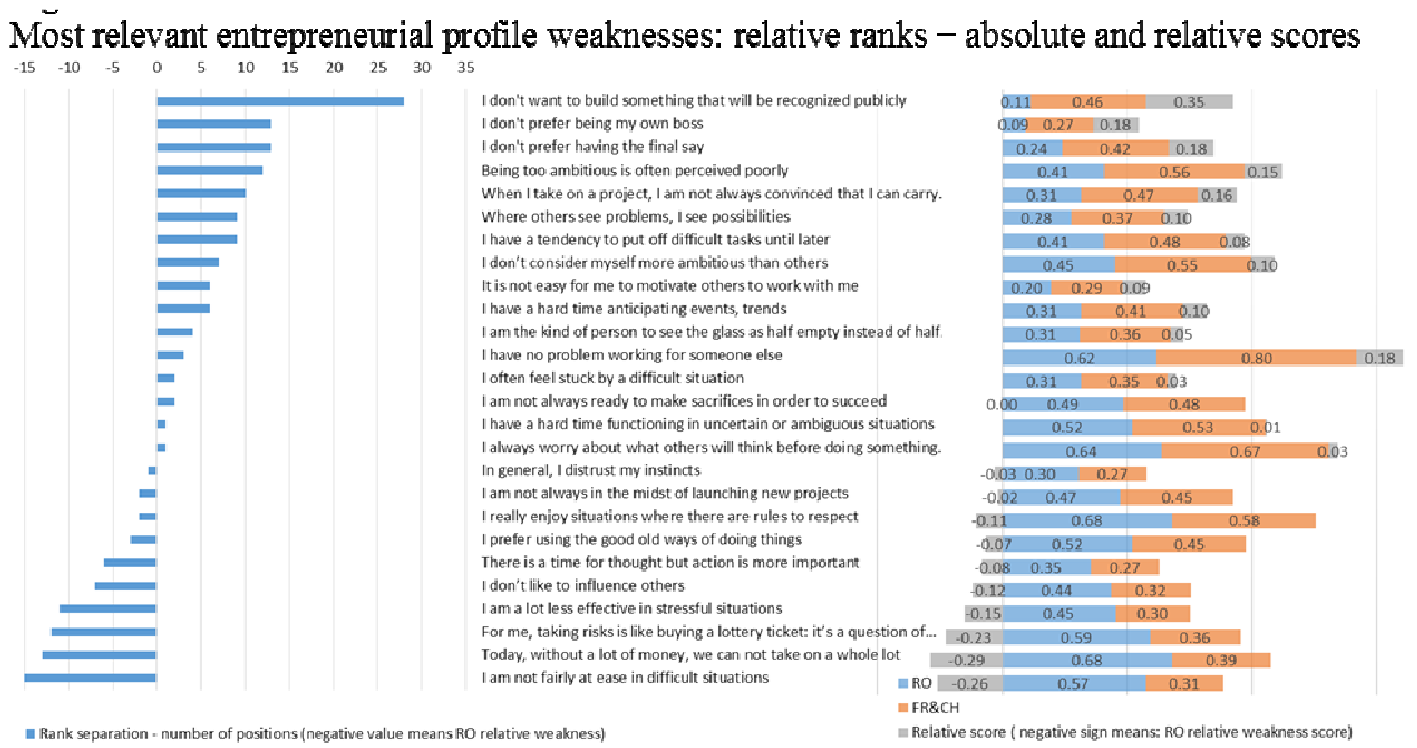

Source: authors' interpretation of data resulted from the questionnaire (2014), previously published in ACEB 2014 - 2014 Asia Conference on Economics \& Business Research - Singapore, November 2014 - Conference Proceedings

\section{Figure 4: Most relevant weaknesses in the entrepreneurial profile}




\section{The clustering of European NUTS 2 regions}

For the cluster analysis of EU regions, we refer to the GDP per capita at current prices (Eurostat reference database: nama_10r_2gdp, nama_10r_2gvagr, nama_10_pc) between 2009 and 2013 (the most recent Eurostat data such as 21 May 2015 for regional data). Thus, in a first phase of aggregation of data for all regions, we apply the classical cluster analysis software and obtain a tree structure (histogram). A number of regions agglutinate in separate clusters with high similarity between them, and with great distances from other (Southern and Eastern - Ireland, ProvenceAlpes-Côte d'Azur - France Andalusia - Spain, Östra Sverige - Sweden, Comunidad de Madrid - Spain, Catalonia - Spain, RhôneAlpes - France Méditerranée - France, Inner London (NUTS 2010) - Great Britain, Lombardy - Italy, Lazio - Italy, South -Italy, Île de France - France ). What can be mentioned about these first regions is that they are large value generators, but they are showing a slowdown in growth rates of gross added value.

Following the analysis, we find that many regions in Germany are found in the same cluster in terms of GDP, which shows a remarkable lack of regional disparities within the country. At the same aggregate level, there is a third cluster with greater geographical coverage of countries and regions including some that joined the European Union post-2000, such as the Mazowieckie region of Poland. This region is a success story in that it has the fastest economic growth in the Union, a rate $7.1 \%$ higher than the European average. It is therefore a possible example of a leap in terms of development within the European Union, in particular for newly adhered countries.

Most countries in the core of the European Union are found in a separate cluster: regions of France, Italy and Germany, UK,
Spain and the Netherlands. The presence of most regions containing the capital of the country in question confirms the hypothesis of the new economic geography centripetal forces. It can thus be appreciated that from the point of view of the level of similarity, these countries have a high degree of approximation that the major urban agglomeration areas.

\section{Policy and action proposals for increasing efficiency in regional innovative entrepreneurial ecosystems from the point of view of territorial capital}

During more than 100 discussions with actors typical for innovation systems at regional and local level in Romania, the following observations could be drawn which show a certain lack of vision on the strategic and critical need to design policies and create special conditions for growth, for entrepreneurship development and impact measures which allow for the valorization of the existing potential of specialists.

1) The need to diversify funding sources and mechanisms of innovative start-ups is not perceived as an imperative one.

2) The need for designing and implementing programs and training actions particularly regarding growth and impact entrepreneurship and explicitly take into account the specificity of entrepreneurial learning is seen as an imperative one.

3) The existence of a chronic stressed mood, pessimistic about the possibilities to generate notable performances in enterprises with growth potential.

4) Reliance on the gaps in entrepreneurial culture as one of the main causes of the lack of entrepreneurial performance.

5) A pronounced skepticism towards the idea of smart specialization and the need to 
design some custom models with impact on the situation and local conditions, on which to develop strategies and requirements for public funding of start-ups .

6) The operation of the national innovation system and regional innovation systems is affected by a defective cooperation between actors, characterized as rather sporadic, and systemic gaps, as well as the almost nonexistent involvement of private donors.

In this sense, we identify several directions for the implementation of public policy, namely:

1. Adopt a phased action plan. Establish clear by local action groups (in agreement with the representatives of civil society, business and academia and research) sectors and areas of impact necessary (the logic of sustainable development) as funding resources to be concentrated, while adopting strategies for smart local / regional specialization.

2 Take measures to offset the deficit of knowledge and cultural gaps related to entrepreneurship growth and impact by:

a. Introducing curricular components, educational programs, master and graduate entrepreneurship studies associated with the specific sectors which provide basic trainings that are critical for the development of local, regional smart specialization perspective.

b. Initiating a national contest for entrepreneurship projects with prizes in financing and venture under first-stage capital conditions / incubator / accelerator to the best projects in priority sectors aimed at developing entrepreneurship. These projects may be financed by a fund "investments-school" specially created which will operate on the principles of venture capital funding. c. Promoting success stories resulting from this competition and the resulting emerging collateral.

3 Take action to compensate the deficit of knowledge and specific expertise of venture financiers.

a. Introducing an intensive training program, taught by people with actual experience in developed markets and, where possible, an internship component in venture capital organizations in developed countries.

b. Calling foreign experts and mentors to supervise (under coaching) the process of evaluation, selection and participation in companies financed by investment fundschool. (The entire activity of the fund will be overseen by experienced foreign experts.

c. Stimulating successful local entrepreneurs to become venture capitalists by tax return of amounts invested in venture arrangements in the early stages.

4. Increasing generation capacity of viable projects through a competition for funding by increasing the number of specialized investment funds created with public funds. Specialization will be industry-based (sectorial) and target impact on different models and the distribution of funds will be regionally balanced and appropriate.

5. Development of infrastructure to stimulate and accelerate the generation of viable projects in addition to universities and university centers capable of providing knowledge intensive services and facilities for incubation / acceleration.

\section{Conclusions}

The conclusions of this paper related mostly to a relatively pessimistic state of affairs, the 
international best practices on the development of ecosystems are still in 'good intentions" stage, without many active steps towards the potential territorial capital development at regional level. In this respect, the paper answers a set of questions about the facts, viewed objectively (through quantitative and qualitative opinions interpreting the evaluation of early- stage entrepreneurs and potential entrepreneurs), but raises another question, namely: how to overcome the current status of the decline in human capital? It is obvious that the answer to such a question can only come from extensive research conducted on multiple planes that involved complex interrelationships between human capital and other types of capital that give consistency and potential to territorial capital. But even in the absence of such research, several courses of action can be drawn.

First, there is the need for a like widespread research, established on a sufficiently comprehensive vision, which can only come from the development of strategic decision makers.

Secondly, it is necessary to take into account the lessons learned from the fact that a positive correlation between research effort and growth or economic development is not automatic, but only if knowledge management policies are closely coordinated with other complementary policies, focusing on strategic management of other components of territorial capital.

Thirdly, any solution would remain at a conceptual level, if the entrepreneurship ecosystem is not prepared and streamlined to withstand such a radical change.

Fourthly, policies to reform the research and entrepreneurship training are needed in order to ensure a close correlation with specialist training policies. Thus, strategic knowledge generation may be more readily exploited locally and nationally.
Fifthly, EU structural funds allocation and contracting and other financial resources should be made on the basis of impact models (social, environmental, systemic), carefully developed from an evolutionary perspective, facilitating the emergence of synergies and success adapted to local specificities, similar to the natural ecological succession and rehabilitation interventions based on their triggering, such as trophic cascades. This requires prior decision adopting a vision of Smart Specialization at local, regional and national level, alternatives an emphasized interdisciplinary research underlying the patterns of impact.

Sixthly, active measures should be provided to generate as many examples of successful innovative entrepreneurs, including the growth and impact entrepreneurs. In other words, they should be seen also as territorial capital assets, essential to improve mood and attitude towards learning and acquiring knowledge and entrepreneurial skills.

Finally, it is necessary to start from the observation that the distribution of territorial capital is not heterogeneous and it tends to spread unevenly, creating centers of expertise (which may be emerging or intelligent). Between these nodes of excellences are those identified in the local development strategies as the ones that have the greatest chances of success and development policies must be differentiated / adapted to their peculiarities. For example, in Romania, Bucharest is the most promising pole from which to start with tangible results a faster development strategy towards a sustainable knowledge-based material.

\section{Acknowledgment}

This work was financially through the project "Routes of academic excellence in doctoral and post-doctoral research- REACH" cofinanced through the European Social Fund, by Sectoral Operational Programme Human Resources Development 2007-2013, contract no POSDRU/59/1.5/S/137926. 
Data collection has been supported through SNF-funded project IZERZO_142306/1 and the author would like to thank Aron Jinaru,

\section{References}

1. Akerlof, G.A. (1970). 'The Market for 'Lemons': Quality Uncertainty and the Market Mechanism'. Quarterly Journal of Economics (The MIT Press)

2. Andriani, L. (2013). Social Capital: a Road Map of Theoretical Frameworks and Empirical Limitations (No. 1). Birkbeck Department of Management., http://www.bbk.ac.uk/management/ourresearch/wp/WP1.pdf, accessed 31 March 2015

3. Anggraeni, E., Den Hartigh, E., \& Zegveld, M. (2007). Business ecosystem as a perspective for studying the relations between firms and their business networks. In ECCON 2007 Annual meeting. http://www.chaosforum.com/docs/nieuws/ bes.pdf accessed 31 March 2015

4. Arrow, KJ., (1962) 'The Economic Implications of Learning by Doing'. Review of Economic Studies (The Review of Economic Studies) 29 (3): 155-73

5. Arrow, KJ., (2009),'Some Developments in Economic Theory Since 1940: An Eyewitness Account', Annual Review of Economics, Vol. 1: 1-16 (June 2009)

6. Battistella, C., Colucci, K., De Toni, A. F., \& Nonino, F. (2013). Methodology of business ecosystems network analysis: A case study in Telecom Italia Future Centre. Technological Forecasting and Social Change, 80(6), 11941210.

7. Becker GS (1964, 1993, 3rd ed.). Human Capital: A Theoretical and Empirical Analysis, with Special Reference to Education. Chicago, University of Chicago Press
Ph.D. and Alexandru Caragea for their support in this respect.

8. Camagni, R., Capello, R., \& Chizzolini, P. (2008). Regional competitiveness: towards a theory of territorial capital. Modelling regional scenarios for the enlarged Europe: European competitiveness and global strategies. Chizzolini P and Frasati R (eds), Springer-Verlag, Berlin.

9. Capello, R. (2007), Regional Economics, London: Routledge.

10.Capello, R., Caragliu, A. And Nijkamp, P. (2011), Territorial Capital and Regional Growth: Increasing Returns in Knowledge Use. Tijdschrift voor economische en sociale geografie, 102: 385-405.

11.Dinga, E (2007). Sisteme disipative, Entropie și Sustenabilitate, http://www.edinga.ro/files/studii/9_ro.pdf Accessed 31 March 2015

12.Drucker, P. (1985), 'The Discipline of Innovation', Harvard Business Review (HBR), May-June, 1985

13. Florida, R. (2002). The Rise of the Creative Class: And how it's transforming work, leisure, community and everyday life. New York: Perseus Book Group

14.Iansiti, M., \& Levien, R. (2002). The New Operational Dynamics of Business Ecosystems: Implications for Policy, Operations and Technology Strategy: Division of Research, Harvard Business School.

15.Iansiti, M., \& Levien, R. (2004). 'Strategy as ecology'. Harvard Business Review, 82(3).

16.Iansiti, M., \& Levien, R. (2004). The keystone advantage: what the new dynamics of business ecosystems mean for strategy, innovation, and sustainability: Harvard Business Press. 
17.Iansiti, M., \& Richards, G. (2006). Information technology ecosystem health and performance: Division of Research, Harvard Business School.

18.Iansiti, M., \& Richards, G. L. (2006). Information Technology Ecosystem: Structure, Health, and Performance. Antitrust Bull., Division of Research, Harvard Business School, 51, 77.

19.Isenberg, DJ. (2011). The entrepreneurship ecosystem strategy as a new paradigm for economic policy: Principles for cultivating entrepreneurship. Institute of International European Affairs, Dublin, Ireland.

20.Isenberg, D.J. (2010). 'How to start an entrepreneurial revolution'. Harvard Business Review, 88(6), 40-50.

21.Jacobides, M. (2013). Creating and Capturing Value in Your Business Ecosystems TedXTalks:

http://www.tedxthessaloniki.com/index.php /talk_video/creating-and-capturing-value-inyour-businessecosystems/\#sthash.wUfQjlTZ.dpuf, Accessed 31 March 2015
22.Lucas, R. (1988), 'On the mechanics of economic development', Journal of Monetary Economics, 22, 3-42.

23.Nistoreanu, B. G., \& Gheorghe, G. (2014). "The Perception of the Academics and Students Regarding the Entrepreneurial Education in Economic Education'. The AMFITEATRU ECONOMIC journal, 16(37).

24.OECD (2001), OECD Territorial Outlook. OECD Publishing

25.Pamfilie, R., Giusca, S., \& Bumbac, R. (2014). 'Academic research-a catalyst for the innovation process within companies in Romania'. The AMFITEATRU ECONOMIC journal, 16(37).

26.Romer, P. (1990), 'Endogenous technological change', Journal of Political Economy, 98, S71-S102.

27.Solow, RM (1956). 'A Contribution to the Theory of Economic Growth'. Quarterly Journal of Economics (The MIT Press) 70 (1): 65-94

28.Stiglitz, J and Greenwald, B. (2014) Creating a Learning Society - A New Approach to Growth, Development and Social Progress, Columbia University Press 